DOI: 10.33727/JRISS.2021.2.27:231-239

\title{
The smart city concept-Improving traffic fluidity, improving citizen safety and creating an integrated computer-aided dispatcher
}

\author{
Adrian Tudor Draghici \\ University of Craiova, Romania \\ E-mail:gorjtudoradrian@gmail.com
}

\begin{abstract}
Rapid urbanization of cities presents challenges related to the infrastructure for government and municipalities - in the context of estimating that in 2050 a percentage of $80 \%$ of the Europe's population shall be concentrated inside large cities and their neighboring areas. As cities grow and expand their services, the administration and governance become increasingly complex. Therefore, it is required to transform cities in order to address the challenges generated by the security of citizens, the social, economic, engineering and environmental security. The regulation of the traffic in Targu Jiu City is made, mainly, by road indicators that establish the priority of passing through the intersection, but also by roundabouts or traffic light intersections. Currently, traffic light intersections are equipped with time intersection machines. The implementation of the interoperability requirements within different fields or within a single field is the task of the responsible public authorities and must be the object of the development and efficiency directions for the future.
\end{abstract}

Keywords. Smart city, infrastructure, traffic fluidity, citizen safety

\section{Introduction}

The State's concern for ensuring the security of the citizen was recorded by the Law No. 15/1999 on the National Security of Romania. Furthermore, the National Security Strategy of Romania consists of the elements defining the concern for the security of the citizen "for a better life in a safer and more prosperous democratic country"; the definition of security bringing to the fore "the state of normalcy to which the citizens, the communities and the State aspire" (The Romania's National Security Strategy).

The above-mentioned programmatic document indicates the objectives to be met in this approach and it conditions their achievement to the operationalization of the concept of "good governance" achieved through an efficient public administration, consolidating independence, efficiency and computerization of justice, citizens' trust in State institutions, and performance of economic and social activities.

Within the European Union, the concept of human security refers to a set of national and European public policies and security strategies allowing the daily security of every citizen. 


\section{Importance of subject approach}

Rapid urbanization of cities presents challenges related to the infrastructure for government and municipalities - in the context of estimating that in 2050 a percentage of $80 \%$ of the Europe's population shall be concentrated inside large cities and their neighboring areas. As cities grow and expand their services, the administration and governance become increasingly complex. Therefore, it is required to transform cities in order to address the challenges generated by the security of citizens, the social, economic, engineering and environmental security.

Thus, it is the question about the capacities of a smarter cities, which includes aspects related to transport, energy management, pollution level, quality of social services, security of citizens at an appropriate level, and if required, transformation of institutions that have the right and obligation to carry out actions and activities aimed at maintaining public order, security of citizen, and adaptation to the new realities brought by the implementation of the IT\&C technology.

\section{Concept description}

The statistics within the European Union show that $70 \%$ of the Europeans live in urban areas and consume $70 \%$ of the generated electricity, while $56.4 \%$ of the Romania population is urban.

The European Union strategy, i.e. "Europe 2020" includes commitments to promote smart cities and investments in ICT infrastructure, as well as development of the related human and social chapter.

\subsection{Smart city features}

The specialised literature (City of Vienna, 2014) shows some features of a city that can be considered smart.

Smart governance: the smart city has a full range of governance services, possessing a solid IT\&C infrastructure, having Public-Private Partnerships that allow it to achieve its goals, practicing open governance, manifesting transparency towards citizen, etc.

$>$ Smart economy: in the smart city, the economic operations are conducted with an e-business and ecommerce support, and the IT\&C innovation has a significant role in the development of the smart city.

$>$ Smart mobility: logistics and transport activities have an IT\&C support; on-line databases, optimization of urban traffic are part of the smart mobility of a city that can be considered smart.

$>$ Smart environment: this feature includes the use of recoverable energy, controlled IT\&C networks, green buildings, pollution control, water and air quality etc.

$>$ Smart population: the population of a smart city should have digital skills of user, should work in a digitalized work environment, should have access to training, should be able to consult and provide data online.

$>$ Smart lifestyle: the population in a smart city has a lifestyle influenced by IT\&C, evolved health and housing services, cultural services, social cohesion environment.

In 2015, the European Economic and Social Committee (EESC) adopted a document laying the basis for the new strategy for the development and support of Smart City projects, as a driver of a new industrial policy in Europe.

In order to propose the development of smart cities in the European Union, EESC supports the investments in such projects with the help of the existing public, European, national and regional funds, and the European Fund for Strategic Investment (EFSI) is involved in this sense.

In case of Romania, the Government Decision No. 929/2014 on the National Strategy for Research, Development and Innovation 2014-2020 was approved, and it includes in para. 3/43 innovative solutions 
for the public sector. Also in 2014, the National Strategy on Digital Agenda for Romania was adopted aiming to increase efficiency and reduce costs in the public sector by modernizing the Romanian administration, and the fields of action are: e-Governance, Cyber Security, Cloud Computing, Open Data, Big Data and Social Media.

The existing discrepancies have economic, social, cultural and, in particular, digital disparities.

An analysis (European Parliament Directorate General for Internal Policies Department A 2014) of the European Parliament shows that in Europe the number of cities that meet each feature would be:

$\begin{array}{ll}- & \text { Smart governance }-85 \\ - & \text { Smart economy -67 } \\ - & \text { Smart mobility - 125 } \\ - & \text { Smart environment - } 199 \\ - & \text { Smart population - 52 } \\ - & \text { Smart lifestyle -71 }\end{array}$

The discrepancies found are related to the economic and organizational power of cities, a higher one in case of large cities, but a more detailed analysis leads to causes related to digital discrepancies.

In Romania there are several initiatives for the implementation of some features of the smart city. However, the articulated and coherent, long-term strategies of a city are not yet completed.

A municipality can establish and develop programs to ensure access to IT by integrating into the urban physical environment such as:

- modern fiber optic networks can provide all buildings with high speed access;

- classic telephone booths made useless by spreading mobile telephony can become free WI-FI access points;

- free WI-FI access is provided in public transport, public institutions, markets, parks, etc.

- combining IT \& C solutions with ecological ones for a cleaner environment and superior living conditions for citizens.

Municipalities in developed cities easily adopt advanced technologies, have greater resources and specialized consulting, most of which are university centers. Cities with overqualified labor force invest less in digital training. In smaller cities it is refractory to the introduction of new technologies.

\subsection{Digital tehnologies and smart cities}

Digital technologies are evolving very fast, faster than any other. One may ask whether smart cities should adopt them immediately or wait for them to mature. The rapid evolution means that, in most cases, their non-adoption harms more than their early adoption.

Among the technologies that can strengthen the status of smart city are listed below:

- Social media posts, an opportunity for urban planning;

- Satellite data used for urban planning;

- Surveillance cameras used for citizen security and traffic flow;

- Intelligent traffic tracking systems based on GPS sensors

- Intelligent public transport tracking systems based on sensors and GPS

- $\quad$ Energy, water and waste resource management systems

- Intelligent street lighting with lighting in the area.

\subsection{Public security}

Public safety and public security include prevention and response measures both in terms of intentional or accidental injuries, as well as in terms of emergencies, calamities or natural disasters.

The safety and security of citizens and their goods should be a permanent concern and responsibility of public authorities. 
According to the Government Decision No. 779/2015 on the approval of the National Strategy for Public Order and Safety for 2015-2020, it is emphasized the importance of the safety and security of citizens for society, and it highlights the strongly denied impact that their lack can have on individuals and communities to which they belong.

Smart technologies, along with mobile technologies, currently allow a wide range of services for citizens. Such smart services, considered important for the community are as follows:

- Measures concerning the safety and security of children and young people inside and within the neighborhood of educational institutions, playgrounds, etc.;

- Measures concerning the security for elderly people;

- Measures concerning the early detection and identification of violent, potentially conflicting or incident-generating situations, such as traffic jams, unauthorized human settlements, etc.

- Measures to facilitate the use of the emergency service under crisis or emergency circumstances that take place in the private or public environment;

- Measures for early detection and information and early warning of citizens regarding climatic conditions, emergencies or other events with potential risk;

- Measures for controlled redirection of car traffic to optimize the movement of vehicles and people.

Specific equipment manufacturers offer a variety of urban security solutions that respond efficiently to threats to citizens' security and contribute significantly to the development of safer cities, such as:

- Facial recognition surveillance systems;

- $\quad$ Solutions for smart buildings;

- Star light and 4k video surveillance solutions;

- Solutions for vehicle identification by recognizing their registration numbers.

\subsection{Electronic interoperability}

The interconnection of equipment and the exchange of data with the environment, or with other equipment and structural or human users is one of the foundations of smart technologies.

Electronic interoperability is thus a basic requirement for a smart service to exist and operate.[11]

Public authorities implementing smart services should consider the need for computer systems and electronic equipment serving the implemented services to have the ability to exchange data with each other, with the environment or with human users.

In this respect, it is necessary for the public authorities to put into practice aspects of syntactic interoperability required for the exchange of data.

It is necessary to take into account the exchange of data between systems of different public authorities.

\subsection{Citizen Participation - an example of good practice, Amsterdam}

A relevant example of "citizen participation" (Ministry of Communication and Information Society Smart City Guide - published on 02.12.2016) through crime networks can be found in Amsterdam, where the Mayor's Office came up with an innovative solution to put citizens in direct contact with the local police. With the help of the media, cooperation is promoted between the police and the citizens, and they are also informed about the results of the police investigations.

Specifically, this project led to the creation of a website, in order to increase involvement among citizens and to materialize the interaction between the two parties, i.e. citizens and the police.

Citizens are in this way put to play a detective role and are asked to come up with useful ideas or scenarios for local police to get a new perspective on specific situations.

The aim of this project can be summarized in two general goals: 
1. Increasing police efficiency by acquiring useful and relevant information about suspects, victims, missing persons, stolen goods, etc. Coming from citizens, this information can be called "witness information".

2. Strengthening the legitimacy of the police by facilitating the understanding by the citizens of the police efforts, the idea that the citizens can be useful in streamlining the police actions, making them more confident on the actions that the police institution undertakes.

The presentation of the project in question indicates the importance of the citizens' participation and of their interest in the processes of ensuring and supervising the public order, respectively their contribution to the supervision of their own security.

4.Improving traffic fluidity, improving citizen safety and integrated computer-aided dispatcher Case Study: Targu Jiu City (Integrated Urban Development Strategy of Targu Jiu City, 2016)

The Project is submitted for funding through the Regional Operational Program, Axis 4.1: Reducing carbon emissions in county seats through investments based on sustainable urban mobility plans.

The total value of the project is Lei 38,125,304.62 of which Lei 37,362,789.52 non-reimbursable value. The project shall be implemented within 42 months from the date of signing the Financing Agreement.

General Objective of the Project

Reducing carbon emissions in Targu Jiu City by implementing the traffic management system.

Specific Objectives of the Project

1. Reducing car traffic and $\mathrm{CO}_{2}$ equivalent emissions from transportation by transferring part of the modal share of private car transport to public transport by improving the efficiency of public passenger transport.

2. Increasing the attractiveness of the public passenger transport system by improving travel times in parallel with reducing the use of transport by personal cars.

\subsection{Project Justification}

The road network of the municipality consists of 292 streets, with a total length of $182 \mathrm{~km}$. Private car transport reaches high values, the inhabitants of Targu Jiu owning a number of 36,846 registered vehicles, which leads to a degree of motorization of 378 vehicles / 1000 inhabitants, a value that is above the national average. For this reason, traffic has become one of the most important problems facing the city, as the existing infrastructure is not able to withstand high volumes of traffic. Currently, the volume / capacity ratio in the main intersections of the municipality is close to the value of 1 , and during peak hours it exceeds this value (Sustainable Urban Mobility Plan Targu Jiu - 2016).

Since it is not possible to increase the capacity of traffic arteries and intersections in the central area of the city, by expanding them, the only solution is to adapt an intelligent traffic management solution to ensure greater traffic flow and optimal distribution of vehicle columns on transport corridors [1-3].

The regulation of the traffic in Targu Jiu City is made, mainly, by road indicators that establish the priority of passing through the intersection, but also by roundabouts or traffic light intersections. In Targu Jiu there are 13 roundabouts and 8 traffic light intersections (of which 4 are roundabouts). Currently, traffic light intersections are equipped with time intersection machines.

The length of the traffic light cycle and the length of the phases can not be changed in real time. There are no road traffic management system and no traffic management center in the city. There is also no dynamic information system at the level of traffic arteries or on the public transport system. At the level of the public transport system, pricing and charging are classic, using paper tickets. Currently, Targu Jiu city has no system for prioritizing public transport vehicles, and the management of intersections is mostly done by markings (horizontal and vertical signaling). 
Road crime is an area of interest for the population, and such interest is related not so much to the statistical evolution of crimes committed in public, but to the social impact generated by this type of crime, thus affecting the sense of security of the citizen.

\subsection{Project Description}

The following shall be implemented:

- A Management Center (command and control), with its own complex architecture, based on a high-speed, state-of-the-art communications platform (IP type) and a server structure that provides the necessary processing power;

- Public transport prioritization system (the main function of the system shall be to take over the information from the field regarding the public transport vehicles and its correlation with the traffic schedule, ensuring the resynchronization of the traffic light diagrams, as necessary);

- Passenger information system (it shall operate both at vehicle and station level and in the online environment, through the mobile application for passenger information);

- Video monitoring system to increase safety;

- ETicketing system (a module for the online sale of travel tickets shall offer travelers both the functionality of purchasing Internet tickets with subsequent reloading of cards, and a series of advanced features for the comfort of passengers in managing the use of public transport services);

- 38 intersections (pedestrian crossings);

- 47 passenger stations equipped with a passenger information panel concerning the waiting time and the lines available within that station, as well as a surveillance video camera with the role of increasing the safety of passengers and equipment within the station (in high-traffic passenger stations -8 stations - vending machines for travel tickets shall be installed);

- 35 buses / trolleybuses registered in the eTicketing system;

- 5 buses / trolleybuses equipped with e-ticketing system;

- information campaign.

\subsection{Components Detail- Implementation of public transport priority system}

The following activities shall be undertaken for this purpose:

- Installation of vehicle \& pedestrian identification and detection equipment at crosswalks, as well as communication systems to ensure predictability functions. Equipping and registration in the system of the entire fleet of vehicles belonging to the operator of the Municipality (TRANSLOC SA) shall be taken into account.

- Installation / adaptation of static horizontal and vertical road signaling elements;

- Installing new traffic light poles, where necessary and repainting and protection of existing poles;

- Elimination of old traffic lights and their replacement by new traffic lights using LED technology that have better visibility, lower maintenance costs and a much longer life. At the same time, they have low energy consumption which is significant in terms of the total number of intersections.

- Construction of overhead electrical channels for road, sidewalk and greenspace;

- Construction of a new manhole, where appropriate;

- Changing the connecting cables of the traffic lights at the intersections where the intervention takes place;

- Identification of supply points and commissioning of the entire system using integrated components for all subsystems;

- Implementation of a modern toll system, e-Ticketing type, which shall cover all the vehicles of the transport operator and which shall provide a modern, efficient and flexible service; 
- Installation of a toll system based on electronic cards both single use and re-rechargeable;

- Installation of validators for travel documents in vehicles, as well as specific telecommunication infrastructure;

- Equipping the points of sale (manual ones) with card recharging devices;

- Installation of a number of vending machines in the public space, i.e. devices able both of distributing new cards and having the possibility to recharge the cards in use;

- Equipping the service of controllers with specific electronic terminals.

- Implementation of the modern solution for informing passengers about the transport schedule and waiting times in stations, in real time, as follows:

- Installation of billboards in stations - the project shall equip 7 new passenger stations, in addition to the 40 ones in progress of implementation through the effort of the Beneficiary;

- Development of an online and mobile information solution, accessible to the general public and which will ensure at least the following types of information:

- $\quad$ Optimal transportation routes between two or more addresses, as well as optimal transport lines;

- $\quad$ The cost of travel depending on the distance, locations, type of tickets, etc.;

- $\quad$ Transport schedule, reported per line, per route or at each station separately - this module shall use updated information according to the movement of vehicles in the field.

- Implementation of an adaptive road traffic management system to include the 38 locations (pedestrian crossings with button and traffic light intersections) with the following advantages: reducing travel time in the city, increasing the average speed for public transport, reducing consumption fuel and pollutant emissions, improving travel times and safety conditions for cyclists and pedestrians by providing automated, electronically controlled crossing areas (button pedestrian crossings);

- Replacement of existing and older design control devices with equipment to allow communication between intersections and integration with the Control Center, introduction of multi-programs or the possibility of adding new equipment or other features (inductive loops, console detectors, cameras video detection, etc.) in order to prioritize vehicles that have the capacity to request it (public transport);

- Installation of communication equipment with buses / trolleybuses, inductive loops for road traffic detectors or suspended sensors, allowing the real and instantaneous determination of the number of vehicles at the intersection. These data allow the control machines with which the intersections shall be equipped to create traffic light times that depend on the real traffic conditions and mainly to ensure the priority for public transport and secondarily to optimize the operation of the intersections;

- A fiber optic communication between intersections and ensuring the connection with the Command Center;

- Increasing the safety of citizens in public transport vehicles and in public space, in general, by equipping traffic light intersections, pedestrian crossings with buttons, public transport stations with a number of 147 surveillance equipment (video cameras);

- Increasing the safety of citizens and alerting the competent institutions in case of entry into the municipality of some vehicles on the list of those pursued, by installing a modern application for recognition and interpretation of registration number;

- Creation of a unique Command Center, for the coordination of traffic management and video surveillance activities that would meet the future development requirements of Targu Jiu City. 
- Identification of the number of operators and required related stations;

- Space development;

- Installation of equipment in the Command and Control Center;

- Implementation of software programs necessary for centralized traffic management;

- Implementation of dedicated applications for metropolitan video surveillance, and image recording, archiving and management;

- Increasing passenger confidence and satisfaction for public transport and, consequently, increasing the number of people using public transport.

The following activities shall be undertaken to achieve this goal:

- Installation of billboards in the field and / or public transport stations that shall display various information of public interest: transfer times through congested routes, waiting times for transport lines, number of parking spaces and / or directing to them, other information;

- Equipping public transport vehicles with road position communication elements, as well as communication elements with infrastructure components of the adaptive traffic management system;

- Information campaign that shall aim to raise public awareness about the use of local public transport.

\section{Conclusions}

Current approaches, studies and projects on urban development mainly consider aspects related to the improvement of the quality of life of residents by optimizing communication facilities, environment, transport, access to public services in general, and the part aimed at ensuring public order and safety of citizens is the responsibility of the institutions with direct attributions in the field, and it is not an integral part of the local development projects.

The development of cities also involves new threats and vulnerabilities, whose appearance is in turn generated by the facilities offered by the development of IT\&C technology.

Considering modern cities, such threats are represented by: electronic information circulation; personalized advertising; manipulating and channeling public opinion towards certain dubious topics or actions and which, often, aim at undermining the authority and legitimacy of public institutions; human trafficking and exploitation of children's vulnerability; spreading the consumption of harmful substances; street crime, infestation of electronic equipment such as - GPS, cards, ATMs, smart phones, computers, databases, etc.

The metropolitan area of Romania experiences a division of the attributions of the institutions that have an operational role regarding the supervision and immediate intervention in the cases in which the safety and security of the citizens is threatened. Thus, it is necessary to draw up protocols to regulate access to databases or specific equipment that one institution or another owns.

At the same time, the operative collaboration between institutions is done through different command centers, specific to each of them, and therefore, the operations carried out regarding the citizen's security are based on a command line organized horizontally, not vertically as it is normal in the case of militarized institutions, or with special attributions in the matter of supervision, and the maintenance of the public order and the safety of the citizens.

In order to solve the issues related to the interoperability of data systems between public authorities, it is necessary to regulate interoperability standards on different areas of interest. An example would be that the police have access to the database owned and operated by the local public administration authorities, by the companies that provide public transport, to the database of the school inspectorates, etc. 
The implementation of the interoperability requirements within different fields or within a single field is the task of the responsible public authorities and must be the object of the development and efficiency directions for the future.

No less important is the reactive attitude of citizens to the threats or potential dangers they notice in society, or proactive towards their own safety. In this sense, an essential component is the communication between institutions and citizens as beneficiaries of the living environment - desired to be in complete safety, both for themselves and for their own goods.

\section{References}

[1] SC ELTRANS PROIECT SRL - Feasibility Study - Rehabilitation, modernization and extension of the public transportation system by trolleybuses - Targu Jiu City, 2019

[2] SC INSTITUTUL DE CERCETARI IN TRANSPORTURI - INCERTRANS S.A. (Transport Research Institute) - Feasibility Study - Traffic study for projects of rehabilitation, modernization and extension of the public transport system with the trolleybus, 2018

[3] SC AM PROJECT DESIGN \&amp; CONSULTING S.R.L. BUCHAREST - Feasibility Study Improving traffic fluidity, improving citizen safety in the public space and creating an integrated computer-aided dispatcher - 2018

[4] SC SMART TECHNOLOGY RESEARCH \& amp;CONSULTING SRL - Feasibility Study Increasing the efficiency of the public lighting system in Targu Jiu City - 2018

[5] Integrated Urban Development Strategy of Targu Jiu City, 2016

[6] Sustainable Urban Mobility Plan Targu Jiu - 2016

[7] ***http://www.targujiu.ro

[8] Energy efficiency improvement program for Targu Jiu City, 2017

[9] Baltac V. (2011) - Information technologies - Basic notions, Andreco Educational Publishing House, Bucharest

[10] Dinca D. (2011) - Mechanism of local development, EIRP Proceedings, Mechanism of globalization, Polirom Publishing House, Iasi

[11]. Vrabie C. (2014) -Elements of IT for public administration, $2^{\text {nd }}$ Edition, Vol. I, Pro Universitaria Publishing House, Bucharest

[12]. Nitu I. (2012) - Intelligence Analysis, Rao Publishing House

[13]. SNSPA, Smart City, 2016, Coordinators Dinca D., Vrabie C., Dumbrava C., Pro Universitaria Publishing House, Bucharest

[14]. Romania's National Defense Strategy, Bucharest, 2016 